\title{
A Joint Scheduling Optimization Model for Wind Power and Energy Storage Systems considering Carbon Emissions Trading and Demand Response
}

\author{
Yin Aiwei, ${ }^{1}$ Xu Congwei, ${ }^{1}$ and Ju Liwei ${ }^{2}$ \\ ${ }^{1}$ School of Economics and Management, Beijing University of Aeronautics and Astronautics, Beijing 100191, China \\ ${ }^{2}$ School of Economics and Management, North China Electric Power University, Beijing 102206, China \\ Correspondence should be addressed to Ju Liwei; 183758841@qq.com
}

Received 16 November 2015; Revised 11 January 2016; Accepted 27 January 2016

Academic Editor: Jinyun Yuan

Copyright (C) 2016 Yin Aiwei et al. This is an open access article distributed under the Creative Commons Attribution License, which permits unrestricted use, distribution, and reproduction in any medium, provided the original work is properly cited.

To reduce the influence of wind power random on system operation, energy storage systems (ESSs) and demand response (DR) are introduced to the traditional scheduling model of wind power and thermal power with carbon emission trading (CET). Firstly, a joint optimization scheduling model for wind power, thermal power, and ESSs is constructed. Secondly, DR and CET are integrated into the joint scheduling model. Finally, 10 thermal power units, a wind farm with $2800 \mathrm{MW}$ of installed capacity, and $3 \times 80 \mathrm{MW}$ ESSs are taken as the simulation system for verifying the proposed models. The results show backup service for integrating wind power into the grid is provided by ESSs based on their charge-discharge characteristics. However, system profit reduces due to ESSs' high cost. Demand responses smooth the load curve, increase profit from power generation, and expand the wind power integration space. After introducing CET, the generation cost of thermal power units and the generation of wind power are both increased; however, the positive effect of DR on the system profit is also weakened. The simulation results reach the optimum when both DR and CET are introduced.

\section{Introduction}

The implementation of China's energy-saving and pollutant emission reduction strategies has prompted large-scale wind power development. In 2014, the installed capacity of wind power reached 115 million $\mathrm{kW}$, ranking first in the world. However, influenced by the intermittency that is characteristic of wind power, the growth rate of wind power grid integration is smaller than the growth rate of the installed capacity. This phenomenon leads to a high rate of curtailed wind power in China. The average rate of curtailed wind power is approximately $12.8 \%$. Especially in the "three north areas," the rate of curtailed wind power has already reached $15.4 \%$. In order to solve the problem of curtailed wind power, suitable backup service should be provided on the generation site for wind power connected to the grid. Energy storage systems (ESSs) could flexibly provide backup service by charging and discharging. This property gives ESSs the most potential as a means to provide backup service for wind power integration. Additionally, demand response (DR) could optimize customers' power consumption behavior and incentivize customers to participate in system scheduling for wind power consumption.

Currently, China is implementing carbon emission trading (CET) pilot projects and plans to establish a CET market to prompt energy-saving and emissions reduction in the "thirteenth five-year plan" period. CET could affect the generation cost of thermal power units and make clean energy generation more advantageous. Hetzer et al. [1] regard carbon emission as a virtual network flow to subsequently build a theoretical framework for carbon emissions from the power system based on analyses of carbon emission trading and developing trends in the power industry. References [24] study carbon emission right definition problems in crossregional power trading and build a fair allocation principle based on the construction of a mathematical model that tracks carbon flow. The above research shows that CET can affect the cost of thermal power generation and make grid 
integration of clean energy more advantageous. Therefore, a study of how to integrate ESSs, DR, and CET into the traditional generation scheduling of a power system with wind power has important practical significance.

Selecting a better backup method is the most effective way to overcome the random nature of wind power. Currently, backup service for wind power grid integration consists of three main parts: thermal power, pumped storage power plants, and ESSs. Jiang et al. [5] develop a wind-thermal economic emission scheduling model considering coordination of the power allocation of thermal units and wind turbines. Yuan et al. [6] establish a multiobjective economic scheduling model for the hydrothermal-wind problem, considering the uncertainty cost of wind power. Wang et al. [7] propose a novel stochastic constraint model to solve for the uncertainty cost of wind power and present an improved particle swarm optimization (PSO) algorithm to solve the proposed model. Thermal power units can provide backup service for wind power by adjusting their start-stop condition, but their fuel consumption and pollution emission are not environmentally friendly. Therefore, pumped storage power stations are a better way to provide backup service. Papaefthymiou et al. [8] achieve high penetration levels of renewable energy in power systems by combining wind power and pumped storage power plants. Papaefthymiou and Papathanassiou [9] propose a novel unit commitment problem model and binary PSO algorithm to find the optimal schedule scheme. Ming et al. [10] calculate the effect of pumped storage power stations on wind power regulation and develop an economic evaluation model for combined wind power and pumped storage systems. Pumped storage power plants have the advantages of saving energy and reducing pollutant emission, but they are not suitable for large-scale application because they are restricted by geographic location and conditions.

The operational theory of ESSs is similar to that of pumped storage power plants, but ESSs have more flexible installation requirements with better prospects for largescale application. Wu et al. [11] take constraints on power generation units and energy storage units into consideration and build a static model for joint operation of wind power and energy storage. Hu et al. [12] combine opportunity and constraint theory and build a joint scheduling model for wind power and energy storage systems considering the uncertainty in wind power output, which is applied with good results. Ding et al. [13] build a wind-storage joint scheduling model considering risk constraints and use a Monte Carlo simulation method to simulate wind power output. GarcíaGonzález et al. [14] improve the power ramp mathematic expression for wind power and build a joint scheduling optimization model for the control of curtailed wind power and energy storage systems.

The researchers cited above have achieved good results in actual applications; however, the high initial investment cost limits the scale of application of energy storage systems. Therefore, other routes are needed to optimize the application of ESSs. DR can optimize customers' power consumption behavior, smooth the demand load curve, and increase the consumption of wind power. Greening [15] puts forward the basic concept of demand response. Niu et al. [16] classify DR into price-based demand response (PBDR) and incentivebased demand response (IBDR). López et al. [17] propose an optimization model for performing load shifting in the context of a smart grid. Nwulu and Xia [18] integrate game theory into dynamic economic emission scheduling considering DR. A framework for optimizing the bidding strategy of a smart distribution company that contains wind farms and responsive loads in the day-ahead energy market is proposed by Ghasemi et al. [19]. Wang et al. [20] construct a modeling framework for an integrated electricity system in which loads become an additional resource.

CET can highlight the environmental friendliness of wind power and increase the advantages of wind power generation [21]. Zhu et al. [22] developed a full-infinite fuzzy stochastic programming method for planning municipal electric power systems associated with greenhouse gas control under uncertainty. Khalid and Savkin [23] developed and tested a methodology for controlling the emissions from a group of microgenerators aggregated in a virtual power plant with wind power. The above papers discussed the impact of CET on system scheduling; the effects of collaborative optimization of CET, ESSs, and DR should be analyzed.

The rest of this paper is organized as follows. Section 2 puts forward a demand response mathematical model. Section 3 presents a model for charging and discharging ESSs. Section 4 establishes the joint scheduling optimization model for wind power and ESSs with and without CET. Section 5 takes 10 thermal units, a wind farm with $2800 \mathrm{MW}$ of installed capacity, and $3 \times 80 \mathrm{MW}$ ESSs as the simulation system and comparatively analyzes the influence of ESSs, DR, and CET on system operation. Section 6 presents the primary conclusions.

\section{Demand Response Model}

Power demand response refers to a situation in which customers dynamically adjust their power consumption behavior according to price, which should guarantee a balance between power supply and demand. From an economic point of view, when electricity price increases, the demand for power should decrease. Part of the power demand during the peak load period will be transferred to other periods, while the other part will be reduced. Thus, for the peak load period, the load reduction consists of three parts: one is load transfer due to an increased electricity price, the second is load reduction, and the third is load transfer due to a reduced electricity price during the valley load period. For the float load period, the load change consists of two parts: one part comes from the peak load period and the other part goes to the valley load period. For the valley load period, the load increase consists of three parts: one is load transfer due to a decreased electricity price, the second part comes from the peak load period, and the third part is new power demand due to the price reduction.

This study defines the power demand during the peak load period, float load period, and valley load period before 
implementing time-of-use (TOU) price as $G_{\text {peak }}, G_{\text {flat }}$, and $G_{\text {valley }}$. Power demand at period $t$ is $G_{t}$; therefore,

$$
\begin{aligned}
G_{\text {peak }} & =\sum_{t \in \text { peak }} G_{t}, \\
G_{\text {flat }} & =\sum_{t \in \text { flat }} G_{t}, \\
G_{\text {valley }} & =\sum_{t \in \text { valley }} G_{t} .
\end{aligned}
$$

The proportion of power demand reduction during the peak load period is given by $\alpha$, the proportion of the load that transfers to other periods is $\alpha_{1}$ and the load loss proportion is $1-\alpha_{1}$, and the proportion of the load that transfers to the float load period is $\alpha_{2}$ and the proportion that transfers to the valley load period is $1-\alpha_{2}$. The proportion of power demand increase during the valley load period is $\beta$, the proportion of the load transferred to the valley load period is $\beta_{2}$, and the new demand proportion is $1-\beta_{2}$. The proportion of the load that comes from the valley load period is $\beta_{2}$, and the proportion from the float load period is $1-\beta_{2}$. Thus, the demand during the peak, float, and valley load periods is calculated as follows:

$$
\begin{aligned}
G_{\text {peak }}^{\prime}= & G_{\text {peak }}-G_{\text {peak }} \cdot \alpha-G_{\text {valley }} \beta \cdot \beta_{1} \cdot \beta_{2}, \\
G_{\text {flat }}^{\prime}= & G_{\text {flat }}+G_{\text {peak }} \cdot \alpha \cdot \alpha_{1} \cdot \alpha_{2}-G_{\text {valley }} \cdot \beta \cdot \beta_{1} \\
& \cdot\left(1-\beta_{2}\right), \\
G_{\text {valley }}^{\prime}= & G_{\text {valley }}+G_{\text {valley }} \cdot \beta+G_{\text {peak }} \cdot \alpha \cdot \alpha_{1} \cdot\left(1-\alpha_{2}\right) .
\end{aligned}
$$

If the proportion of load change is the same at each point in time in the same period, the load at each time point is

$$
\begin{aligned}
& G_{t}^{\prime}=\frac{G_{t}}{G_{\text {peak }}} G_{\text {peak }}^{\prime} \quad t \in \text { peak, } \\
& G_{t}^{\prime}=\frac{G_{t}}{G_{\text {flat }}} G_{\text {flat }}^{\prime} \quad t \in \text { flat, } \\
& G_{t}^{\prime}=\frac{G_{t}}{G_{\text {valley }}} G_{\text {valley }}^{\prime} \quad t \in \text { valley. }
\end{aligned}
$$

The system load period will change from $G_{t}$ to $G_{t}^{\prime}$ with the introduction of DR; load demand reduces during the peak load period and increases during the valley load period. The demand load curve becomes smoother after peak load shifting.

\section{Charging and Discharging Model for ESSs}

ESSs can be regarded as both power resources and load demand. When wind power output is high at night, ESSs are regarded as load demand. In the daytime, they are regarded as power resources to meet load demand. Charge and discharge of ESSs are limited by the system capacity. Assuming the storage energy of ESSs at time $t$ is $Q_{s, t}$, the charging and discharging power balance should obey

$$
Q_{s, t}=Q_{s, t-1}+Q_{s, t}^{+}-\frac{Q_{s, t}^{-}}{\left(1-\theta_{s}\right)},
$$

where $Q_{s, t}^{+}$is the charging power at time $t, Q_{s, t}^{-}$is the discharging power at time $t$, and $\theta_{s}$ is the loss coefficient for charging and discharging power.

Charging and discharging power from ESSs is limited as follows:

$$
\begin{aligned}
& Q_{s, t}^{+} \leq \overline{Q_{s}}, \\
& Q_{s, t}^{-} \leq \overline{Q_{s}},
\end{aligned}
$$

where $\overline{Q_{s}}$ is the upper limit for charging and discharging power.

In addition, the energy storage capacity of ESSs is limited:

$$
Q_{s, t}<Q_{s}^{\max }
$$

where $Q_{s}^{\max }$ is the maximum storage capacity of the ESSs.

\section{Scheduling Model for Wind Power and ESSs}

\subsection{Mathematical Model without CET}

4.1.1. Objective Function. Wind farm operators hope for higher consumption of wind power to gain more profits; however, this will cause more frequent adjustment of thermal power units for peak regulation, improving wind power grid integration but also increasing system coal consumption. To achieve the optimum energy efficiency, a joint optimization scheduling model for wind power and thermal power is built. The maximum total profit of ESSs, wind power, and thermal power is taken as the optimization objective:

$$
\max z_{1}=\pi_{c}+\pi_{w}+\pi_{s},
$$

where $\pi_{w}, \pi_{c}$, and $\pi_{s}$ are the profits of wind farms, thermal power units, and ESSs, respectively.

The wind farm profit is calculated as follows:

$$
\pi_{w}=p_{w} \sum_{t=1}^{T} Q_{w, t}\left(1-\theta_{w}\right)-\mathrm{OM}_{w}-D_{w} .
$$

The profit of thermal power units is calculated as follows:

$$
\pi_{c}=p_{c} \sum_{i=1}^{I} \sum_{t=1}^{T} Q_{i, t}\left(1-\theta_{c, i}\right)-C_{\text {fuel }}-\sum_{i=1}^{I} \mathrm{OM}_{c, i}-\sum_{i=1}^{I} D_{c, i},
$$

where $p_{c}$ is the benchmark price of thermal power, $Q_{i, t}$ is the real-time power generation of unit $i$ at time $t, \theta_{c, i}$ is the power consumption rate of unit $i, C_{\text {fuel }}$ is the fuel cost for power generation, $\mathrm{OM}_{c, i}$ is the operation and maintenance cost of unit $i$, and $D_{c, i}$ is the depreciation cost of unit $i$.

The fuel cost of a thermal power unit is calculated by

$$
\begin{aligned}
& C_{\text {fuel }}=\sum_{i=1}^{I} \sum_{t=1}^{T}\left[p_{\text {coal }} u_{i, t} f_{i}\left(Q_{i, t}\right)+u_{i, t}\left(1-u_{i, t-1}\right) \mathrm{SU}_{i}\right. \\
& \left.\quad+u_{i, t-1}\left(1-u_{i, t}\right) \mathrm{SD}_{i}\right]
\end{aligned}
$$


where $p_{\text {coal }}$ is the standard coal purchase price, $u_{i, t} f_{i}\left(Q_{i, t}\right)$ is the standard coal consumption, and $u_{i, t}$ is a binary variable. When a thermal power unit is shut down, coal consumption is zero, when the thermal power unit is operating, coal consumption is determined by the consumption characteristics function $f_{i}(\cdot)$ and the real-time power output $Q_{i, t}$ :

$$
f_{i}\left(Q_{i, t}\right)=a_{i}+b_{i} Q_{i, t}+c_{i} Q_{i, t}^{2},
$$

where $a_{i}, b_{i}$, and $c_{i}$ are coal consumption parameters of unit $i$, $u_{i, t}\left(1-u_{i, t-1}\right) \mathrm{SU}_{i}$ is the start-up cost of unit $i$ at time $t, \mathrm{SU}_{i}$ is the start-up cost of unit $i, u_{i, t-1}\left(1-u_{i, t}\right) \mathrm{SD}_{i}$ is the shutdown cost of unit $i$ at time $t$, and $\operatorname{SD}_{i}$ is the shutdown cost of unit $i$ :

$$
\pi_{s}=p_{s, \operatorname{char}} \sum_{t=1}^{T} Q_{s, t}^{+}-p_{s, \operatorname{disc}} \sum_{t=1}^{T} Q_{s, t}^{-}-F_{s},
$$

where $p_{s, \text { char }}$ is the electricity price when charging ESSs, $p_{s \text {, disc }}$ is the electricity price when discharging, and $F_{s}$ is the fixed cost of the ESSs.

4.1.2. Constraint Conditions. In the joint optimization model, the constraints of demand and supply balance, thermal power unit operation, wind power operation, and ESS operation should be comprehensively considered.

(1) System Demand and Supply Balance Constraint. Before $\mathrm{DR}$, the system demand and supply balance constraint is described by

$$
\begin{aligned}
& \sum_{i=1}^{I} u_{i, t} Q_{i, t}\left(1-\theta_{i}\right)+Q_{w, t}\left(1-\theta_{w}\right)+Q_{s, t}^{-} \\
& \quad=\frac{G_{t}}{(1-l)}+Q_{s, t}^{+} .
\end{aligned}
$$

After DR, the constraint is described by

$$
\begin{aligned}
& \sum_{i=1}^{I} u_{i, t} Q_{i, t}\left(1-\theta_{i}\right)+Q_{w, t}\left(1-\theta_{w}\right)+Q_{s, t}^{-} \\
& \quad=\frac{G_{t}^{\prime}}{(1-l)}+Q_{s, t}^{+} .
\end{aligned}
$$

(2) Thermal Power Unit Power Generation Constraint. Realtime generation output is limited by the installed capacity and the minimum generation output:

$$
u_{i, t} \underline{Q_{i}} \leq Q_{i, t} \leq u_{i, t} \overline{Q_{i}} .
$$

(3) Unit Ramp Rate Constraint. Depending on the technology level, unit generation output change is constrained by the adjacent period. The real-time output increment and decrement should obey

$$
\Delta Q_{i}^{-} \leq Q_{i, t}-Q_{i, t-1} \leq \Delta Q_{i}^{+} .
$$

(4) Unit Start-Stop Time Constraints. Frequent start-stop affects the performance of a thermal unit. The continuous unit start-stop constraint is shown as follows:

$$
\begin{aligned}
& \left(T_{i, t-1}^{\mathrm{on}}-M_{i}^{\mathrm{on}}\right)\left(u_{i, t-1}-u_{i, t}\right) \geq 0, \\
& \left(T_{i, t-1}^{\mathrm{off}}-M_{i}^{\mathrm{off}}\right)\left(u_{i, t}-u_{i, t-1}\right) \geq 0 .
\end{aligned}
$$

Equation (17) is the shortest time constraint on unit $i$. $T_{i, t-1}^{\mathrm{on}}$ is the continuous running time of unit $i$ at time $t-1$. $M_{i}^{\text {on }}$ is the shortest running time of unit $i$. Equation (18) is the shortest shutdown time constraint on unit $i . T_{i, t-1}^{\text {off }}$ is the continuous shutdown time of unit $i$ at time $t-1 . M_{i}^{\text {off }}$ is the unit shortest shutdown time.

(5) Wind Power Output Constraint. The real-time wind power output is constrained by the wind farm capacity:

$$
Q_{w, t} \leq \delta_{t} P_{w}
$$

where $\delta_{t}$ is the equivalent utilization efficiency and $P_{w}$ is the total installed capacity of wind farm $w$.

(6) Charging and Discharging Power Constraint on ESSs. For ESSs, the cumulative charging and discharging power should obey

$$
\sum_{t=1}^{T} Q_{s, t}^{+}\left(1-\theta_{s}\right)=\sum_{t=1}^{T} Q_{s, t}^{-}
$$

Therefore, if ESS operators hope to profit, the charging and discharging prices should obey

$$
p_{s, \text { char }}>\frac{p_{s, \text { disc }}}{\left(1-\theta_{s}\right)}
$$

(7) System Generation Reserve Constraints. When the power system is in operation, fluctuations may happen on both the generation side and the demand side. To ensure real-time balance, the supply of power should be adjusted to fall within a certain margin by increasing or reducing the power output:

$$
\begin{aligned}
& \sum_{i=1}^{I} u_{i, t}\left(Q_{i, t}^{\max }-Q_{i, t}\right)\left(1-\theta_{i}\right) \geq R_{t}^{\mathrm{usr}}, \\
& Q_{i, t}^{\max }=\min \left(u_{i, t-1} \overline{Q_{i}}, Q_{i, t-1}+\Delta Q_{i}^{+}\right) \cdot u_{i, t-1}, \\
& R_{t}^{\mathrm{usr}}=\beta_{c} \sum_{i=1}^{I} Q_{i, t}+\beta_{w} Q_{w, t} .
\end{aligned}
$$

Equations (22)-(24) are the system upward spinning reserve constraints. $Q_{i, t}^{\max }$ is the maximum possible output of unit $i$ at time $t$. $R_{t}^{\text {usr }}$ is the upward spinning reserve demand, depending on thermal and wind generation power in the corresponding period. $\overline{Q_{i}}$ is the maximum possible energy generation by unit $i$ at time $t$, adjusted for the installed capacity. $\Delta Q_{i}^{+}$is the upward ramp rate, namely, the maximum 
power generation in the adjacent period. $\beta_{c}$ is the thermal power unit reserve coefficient. $\beta_{w}$ is the power reserve coefficient for wind turbines:

$$
\begin{aligned}
& \sum_{i=1}^{I} Q_{i, t}\left(Q_{i, t}-Q_{i, t}^{\min }\right)\left(1-\theta_{i}\right) \geq R_{t}^{\mathrm{dsr}}, \\
& Q_{i, t+1}^{\min }=\max \left(u_{i, t} \underline{Q_{i}}, Q_{i, t}-\Delta Q_{i}^{-}\right) \cdot u_{i, t}, \\
& R_{t}^{\mathrm{dsr}}=\beta_{w} Q_{w, t} .
\end{aligned}
$$

Equations (25)-(27) are the system downward spinning reserve constraints. $Q_{i, t}^{\min }$ is the minimum possible output of unit $i$ at time $t$, restricted by two factors, namely, the minimum possible generation capacity under operation and the unit downward ramp rate constraint. $R_{t}^{\mathrm{dsr}}$ is the system downward spinning reserve demand, depending on wind power in the corresponding period. $Q_{i}$ is the minimum possible generation capacity of unit $i$, adjusted for the realtime minimum power output. $\Delta Q_{i}^{-}$is the unit downward ramp rate, that is, the maximum power reduction generation unit in the adjacent period.

4.2. Mathematical Model with CET. Currently, China is performing pilot construction and planning to establish a CET market in the "thirteenth five-year plan" period. $\mathrm{CO}_{2}$ emission from the thermal power industry accounts for approximately $40 \%$ of the total. Generation rights displacement and the CET mechanism are both market mechanisms to optimize the thermal industry structure and reduce energy consumption and emission, which are consistent in purpose and results.

The marginal generation cost of thermal power changes under a CET mechanism, and carbon emission parameters are different due to different unit technologies, so the generation scheduling plan also changes. To maximize system profit under a carbon trading mechanism, this study builds an optimization model with the objective of maximizing thermal and wind power profit:

$$
\max z_{2}=\pi_{c}+\pi_{w}+\pi_{s} .
$$

Thermal power profit should meet the following conditions:

$$
\begin{aligned}
& \pi_{c}=p_{c} \sum_{i=1}^{I} \sum_{t=1}^{T} Q_{i, t}\left(1-\theta_{c, i}\right)-C_{c}-\sum_{i=1}^{I} \mathrm{OM}_{c, i}-\sum_{i=1}^{I} D_{c, i} \\
& C_{c}=C_{\text {fuel }}+C_{\mathrm{CO}_{2}},
\end{aligned}
$$

where $\mathrm{C}_{\mathrm{CO}_{2}}$ is the cost of carbon emission:

$$
C_{\mathrm{CO}_{2}}=\left(E_{\mathrm{CO}_{2}}-E_{0}\right) p_{\mathrm{CO}_{2}}
$$

where $E_{\mathrm{CO}_{2}}$ is the actual carbon emission of thermal units during the operation period, $E_{0}$ is the total initial carbon emission right, and $\mathrm{P}_{\mathrm{CO}_{2}}$ is the carbon trading price, which is related to the carbon trading demand. To simplify the model, this study assumes that the price does not change with the carbon trading demand.
The actual carbon emission of thermal units is related to the power load rate. Generally speaking, the actual carbon emission of units can be expressed as a quadratic function, similar to (22):

$$
E_{i}\left(Q_{i, t}\right)=a_{\mathrm{CO}_{2}, i}+b_{\mathrm{CO}_{2}, i} Q_{i, t}+c_{\mathrm{CO}_{2}, i} Q_{i, t}^{2},
$$

where $a_{\mathrm{CO}_{2}, i}, b_{\mathrm{CO}_{2}, i}$, and $c_{\mathrm{CO}_{2}, i}$ are parameters of the carbon emission function.

Then, total system emissions are as follows:

$$
E_{\mathrm{CO}_{2}}=\sum_{t=1}^{T} \sum_{i=1}^{I} E_{i}\left(Q_{i, t}\right) .
$$

Scheduling and operation constraint conditions for wind power and ESSs should be considered comprehensively in carbon emissions trading. The system demand and supply constraints, wind power unit operation constraints, and ESSs operation constraints are shown in (13) to (27).

In the mathematical model without CET, (10), (11), (17), (18), and (31) are nonlinear constraints, which are inconvenient to solve. Therefore, they should be linearized. The details of this process can be found in the literature [24, 25].

\section{Example Analysis}

5.1. Case Descriptions. To analyze the impact of ESSs, DR, and CET on system operation, four cases are set up as follows.

Case 1 (baseline case). Self-scheduling of the system without DR and CET: DR and CET are not considered, so the impact of ESSs on wind power grid integration is analyzed alone in this case. The ESS capacity is $3 \times 80 \mathrm{MW}$, the charging and discharging power of a single ESS unit is $20 \mathrm{MW}$, and the charging and discharging loss coefficient is $15 \%$.

Case 2 (self-scheduling of the system with DR). Demand response is introduced into the joint scheduling. The demand load curve is divided into peak, valley, and float load periods according to the literature [24], which are listed in Table 1 . The values of $\alpha_{1}$ and $\alpha_{2}$ are 0.95 and 0.7 , respectively, $\beta_{1}$ and $\beta_{2}$ are 0.90 and 0.40 , respectively, and both $\alpha$ and $\beta$ are $5 \%$.

Case 3 (self-scheduling of the system with CET). $90 \%$ of $\mathrm{CO}_{2}$ emissions from Case 1 are taken as the initial baseline for carbon emission trading, with a carbon emissions trading price of $80 ¥ / \mathrm{t}$.

Case 4 (self-scheduling of the system with DR and CET). Collaborative optimization of CET and DR is analyzed with joint scheduling of wind power and ESSs.

5.2. Basic Data. This study uses 10 thermal power units and a wind farm with an installed capacity of $2800 \mathrm{MW}$ as the simulation system. Coal consumption and carbon emission parameters of the thermal power units are listed in Table 2, and the operation coefficients are listed in Table 3 . The grid purchase price of wind power is assumed to be $540 ¥ / \mathrm{MW} \cdot \mathrm{h}$, the total operation and depreciation cost is 600 million/year, 
TABle 1: Period division of TOU.

\begin{tabular}{lccc}
\hline Load & Valley load period & Float load period & Peak load period \\
\hline Period & $0: 00-6: 00 ; 22: 00-24: 00$ & $6: 00-9: 00 ; 14: 00-19: 00$ & $9: 00-14: 00 ; 19: 00-22: 00$ \\
\hline
\end{tabular}

TABLE 2: Coal consumption and carbon emission parameters of thermal power units.

\begin{tabular}{|c|c|c|c|c|c|c|}
\hline Unit & $a_{j}$ & $b_{j}$ & $c_{j}$ & $a_{\mathrm{CO}_{2}, i}$ & $b_{\mathrm{CO}_{2, i}}$ & $c_{\mathrm{CO}_{2}, i}$ \\
\hline $1 \#$ & 11.6 & 0.260 & $1.88 E-05$ & 29.04 & 0.680 & $1.60 E-05$ \\
\hline $2 \#$ & 9.7 & 0.259 & $6.55 E-06$ & 24.77 & 0.713 & $2.04 E-05$ \\
\hline $3 \#$ & 8.8 & 0.268 & $9.44 E-06$ & 22.64 & 0.747 & $2.86 E-05$ \\
\hline $4 \#$ & 8.4 & 0.273 & $1.65 E-05$ & 21.54 & 0.754 & $4.67 E-05$ \\
\hline $5 \#$ & 7.2 & 0.28 & $2.17 E-05$ & 18.97 & 0.793 & $6.26 E-05$ \\
\hline $6 \#$ & 6.1 & 0.285 & $3.39 E-05$ & 15.80 & 0.788 & $9.37 E-05$ \\
\hline 7\# & 5.2 & 0.292 & $3.42 E-05$ & 13.57 & 0.818 & $9.65 E-05$ \\
\hline $8 \#$ & 4.6 & 0.304 & $4.13 E-05$ & 12.18 & 0.859 & $12.03 E-05$ \\
\hline 9\# & 3.5 & 0.306 & $3.63 E-05$ & 9.35 & 0.876 & $10.96 E-05$ \\
\hline $10 \#$ & 1.4 & 0.314 & $8.35 E-05$ & 3.82 & 0.900 & $24.06 E-05$ \\
\hline
\end{tabular}

TABLE 3: Operation coefficients of coal-fired power units.

\begin{tabular}{|c|c|c|c|c|c|c|c|}
\hline Unit & $\overline{Q_{i}}(\mathrm{MW})$ & $\underline{Q_{i}}(\mathrm{MW})$ & $\Delta Q_{i}^{+}(\mathrm{MW} / \mathrm{h})$ & $\Delta Q_{i}^{-}(\mathrm{MW} / \mathrm{h})$ & $M_{i}^{\text {on }}(\mathrm{h})$ & $M_{i}^{\text {off }}(\mathrm{h})$ & $\theta_{i}(\%)$ \\
\hline $1 \#$ & 250 & 600 & 280 & -280 & 8 & 8 & 4.9 \\
\hline $2 \#$ & 200 & 500 & 240 & -240 & 8 & 8 & 5.3 \\
\hline $3 \#$ & 200 & 450 & 210 & -210 & 7 & 7 & 5.2 \\
\hline $4 \#$ & 180 & 400 & 180 & -180 & 7 & 7 & 5.7 \\
\hline $5 \#$ & 150 & 350 & 150 & -150 & 6 & 6 & 6.1 \\
\hline $6 \#$ & 150 & 300 & 150 & -150 & 5 & 5 & 6.8 \\
\hline 7\# & 120 & 300 & 120 & -120 & 4 & 4 & 6.9 \\
\hline $8 \#$ & 100 & 250 & 100 & -100 & 4 & 4 & 7.3 \\
\hline 9\# & 70 & 150 & 70 & -70 & 3 & 3 & 8.3 \\
\hline $10 \#$ & 30 & 100 & 50 & -50 & 2 & 2 & 8.7 \\
\hline
\end{tabular}

the grid purchase price of thermal power is $380 ¥ / \mathrm{MW} \cdot \mathrm{h}$, and the price of standard coal is $800 ¥ / \mathrm{t}$. The wind power unit equivalent utilization rate and system load distribution are set according to the literature [22] and listed in Table 4.

5.3. Simulation Results. The simulation was implemented in GAMS optimization software using the CPLEX 11.0 linear solver from ILOG_solver. The CPU time required for solving the problem for different case studies with an idea pad450 series laptop computer powered by a core T6500 processor and $4 \mathrm{~GB}$ of RAM was less than $10 \mathrm{~s}$.

5.3.1. Case 1: Self-Scheduling of the System without DR or CET. This case mainly analyzes the impact of ESSs on wind power grid integration. The scheduling result is shown in Figure 1, in which the maximum load is $2860 \mathrm{MW}$, the minimum load is $1230 \mathrm{MW}$, and the peak-valley ratio is 2.33 . The maximum load for the thermal power equivalent output curve is $2458 \mathrm{MW}$, the minimum load is $204 \mathrm{MW}$, and the peak-valley ratio is 12.07 . Figure 1 shows the wind and thermal power outputs.
After introducing ESSs, the peak-valley ratio is 2, the coal consumption rate is reduced from $326 \mathrm{~kg} / \mathrm{MWh}$ to $322.5 \mathrm{~kg} / \mathrm{MWh}$, the system profit is enhanced by 160000 yuan, the electricity from wind power delivered to the grid is increased from 16840.5 MWh to $18620.6 \mathrm{MWh}$, and the curtailed wind power rate is reduced by $8.1 \%$. ESSs can smooth the demand load curve, provide backup service for wind power, and reduce the start-stop cost of thermal power units. The scheduling optimization results for the power system with and without ESSs are listed in Table 5.

If ESS operators hope to maximize their economic benefit in the optimization period, they should discharge all stored energy to gain more economic benefit. However, to reduce the impact of wind power output fluctuation, ESSs make charging and discharging decisions based on wind power output to reduce thermal power peak regulation, as shown in Figure 2. The ESSs charge when wind power output increases and discharge when wind power output decreases.

Total profit declines with addition of ESSs, due to their high investment cost and the lack of large-scale commercial production. China has gradually become concerned with large-scale ESS development; in the long term, it has great 
TABLE 4: Equivalent utilization of wind power units.

\begin{tabular}{|c|c|c|c|c|c|c|c|c|}
\hline Period & Load/MW & Utilization rate/\% & Period & Load/MW & Utilization rate $/ \%$ & Period & Load & Utilization rate/\% \\
\hline 1 & 1100 & 33 & 9 & 2300 & 28 & 17 & 1700 & 32 \\
\hline 2 & 1200 & 55 & 10 & 2500 & 11 & 18 & 1900 & 29 \\
\hline 3 & 1400 & 68 & 11 & 2600 & 26 & 19 & 2100 & 17 \\
\hline 4 & 1600 & 76 & 12 & 2500 & 23 & 20 & 2500 & 13 \\
\hline 5 & 1700 & 67 & 13 & 2400 & 12 & 21 & 2300 & 23 \\
\hline 6 & 1900 & 51 & 14 & 2300 & 20 & 22 & 1900 & 38 \\
\hline 7 & 2000 & 36 & 15 & 2100 & 9 & 23 & 1500 & 33 \\
\hline 8 & 2100 & 32 & 16 & 1800 & 21 & 24 & 1300 & 38 \\
\hline
\end{tabular}

TABLE 5: Scheduling optimization result of power system in different cases.

\begin{tabular}{lccccccc}
\hline & $\begin{array}{c}\text { Wenerating } \\
\text { capacity } \\
(\mathrm{MWh})\end{array}$ & $\begin{array}{c}\text { Grid } \\
\text { proportion } \\
(\%)\end{array}$ & $\begin{array}{c}\text { Curtailed } \\
\text { wind power } \\
\text { rate }(\%)\end{array}$ & $\begin{array}{c}\text { Generating } \\
\text { capacity } \\
(\text { MWh })\end{array}$ & $\begin{array}{c}\text { Thermal power } \\
\text { Grid } \\
\text { proportion } \\
(\%)\end{array}$ & $\begin{array}{c}\text { Curtailed } \\
\text { wind power } \\
\text { rate }(\%)\end{array}$ & $\begin{array}{c}\text { System profit }\left(10^{4} \text { yuan) }\right. \\
\text { Without ESSs }\end{array}$ \\
\hline With ESSs & 16840.5 & 31.2 & 24 & 37032.6 & 68.8 & 326 & 294 \\
\hline
\end{tabular}

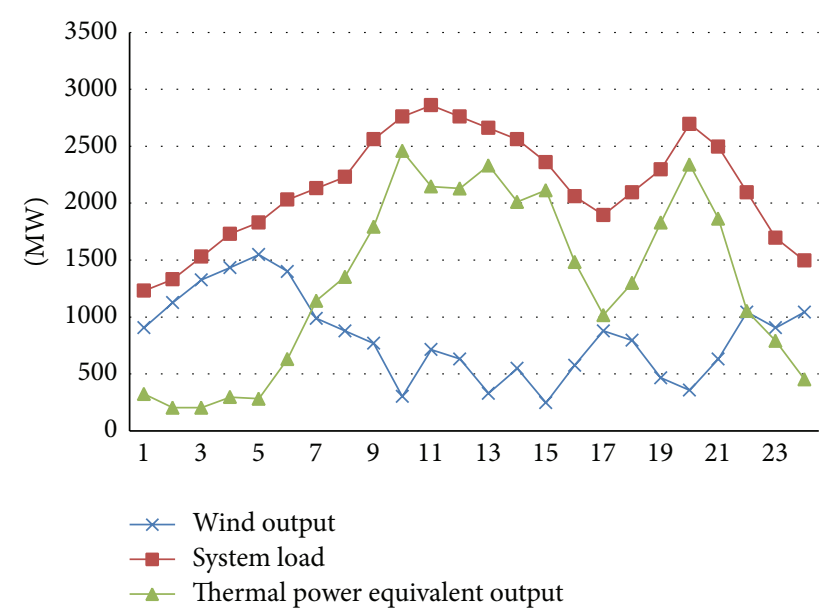

FIGURE 1: Output distribution of wind power and thermal power.

potential with the establishment of price mechanisms and mature technology.

5.3.2. Case 2: Self-Scheduling of the System with DR. The impact of DR on joint scheduling is analyzed in this case. DR can optimize customers' power consumption behavior and smooth the demand load curve. With $\alpha$ and $\beta$ assumed to equal $3 \%$, the system load curves for the two cases are shown in Figure 3.

According to Figure 3, the peak-valley differences for the two cases are $1400 \mathrm{MW}$ and $1252 \mathrm{MW}$, respectively. The peakvalley ratios are 2.33 and 2 . DR can smooth the demand load curve and reduce the curtailed wind power rate, which is $15.9 \%$ in Case 1 and $13.8 \%$ in Case 2. The utilization rate of wind power increases. The system scheduling optimization results for Case 2 are outlined in Table 6.

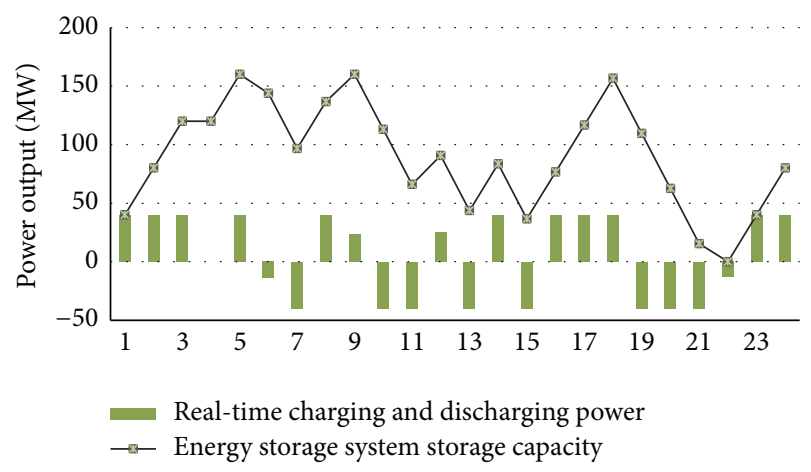

FIGURE 2: Charge and discharge optimization result for ESSs.

5.3.3. Case 3: Self-Scheduling of the System with CET. The impact of CET on the joint scheduling problem is analyzed in this case. The CET price is 100 yuan/t. $98 \%$ of total emissions in Case 1 are taken as the initial carbon emission permit, namely, 26171.73. The output of the thermal power units with different carbon trading prices is shown in Figure 4.

With a carbon trading price of $100 ¥ / t$, the output of wind power increased by $470.21 \mathrm{MWh}$, and the curtailed wind power rate decreased to $13.78 \%$. CET would increase the cost of thermal power generation and change the system scheduling plan. The output of units with high carbon emission coefficient decreased, for example, unit 2 and unit 3. The output of units with low carbon emission coefficient rose, for example, unit 5 . The optimization scheduling result in Case 3 is given in Table 6.

Compared with Cases 1 and 3, CET can increase the cost of thermal power generation and enhance the competitive advantage of wind power. System coal consumption decreased by 3.2072 million yuan, which is lower than that for Case 2. Profit increased to 2.9445 million yuan with increased wind power integration, which is lower than that for Case 2. 
TABLE 6: System scheduling optimization results under different cases.

\begin{tabular}{|c|c|c|c|c|c|c|c|}
\hline \multirow[b]{2}{*}{ Scenario } & \multirow[b]{2}{*}{$\begin{array}{l}\text { Generating } \\
\text { capacity } \\
\text { (MWh) }\end{array}$} & \multicolumn{2}{|l|}{ Wind power } & \multicolumn{3}{|c|}{ Thermal power } & \multirow[b]{2}{*}{ System profit $\left(10^{4}\right.$ yuan $)$} \\
\hline & & $\begin{array}{c}\text { Grid } \\
\text { proportion } \\
(\%)\end{array}$ & $\begin{array}{l}\text { Curtailed } \\
\text { wind power } \\
\text { rate }(\%)\end{array}$ & $\begin{array}{c}\text { Generating } \\
\text { capacity } \\
(\mathrm{MWh})\end{array}$ & $\begin{array}{l}\text { Grid } \\
\text { proportion } \\
(\%)\end{array}$ & $\begin{array}{l}\text { Curtailed } \\
\text { wind power } \\
\text { rate }(\%)\end{array}$ & \\
\hline Case 1 & 18620.60 & 35.40 & 15.90 & 35252.50 & 64.60 & 322.50 & 290.00 \\
\hline Case 2 & 19124.70 & 35.50 & 15.77 & 34748.40 & 64.50 & 318.72 & 301.54 \\
\hline Case 3 & 19090.81 & 35.44 & 13.78 & 34782.29 & 64.56 & 320.60 & 294.45 \\
\hline Case 4 & 19354.72 & 35.93 & 12.58 & 34518.38 & 64.07 & 314.82 & 312.72 \\
\hline
\end{tabular}

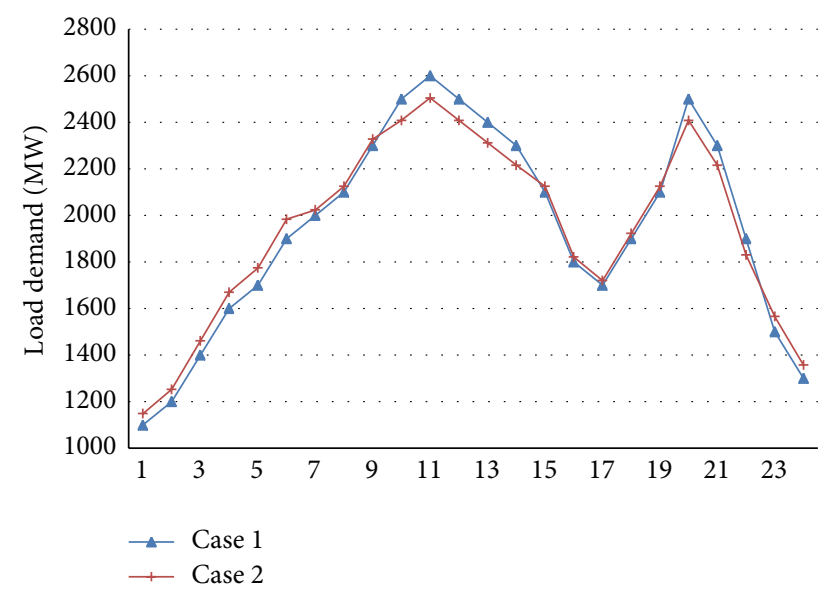

Figure 3: System load under different cases.

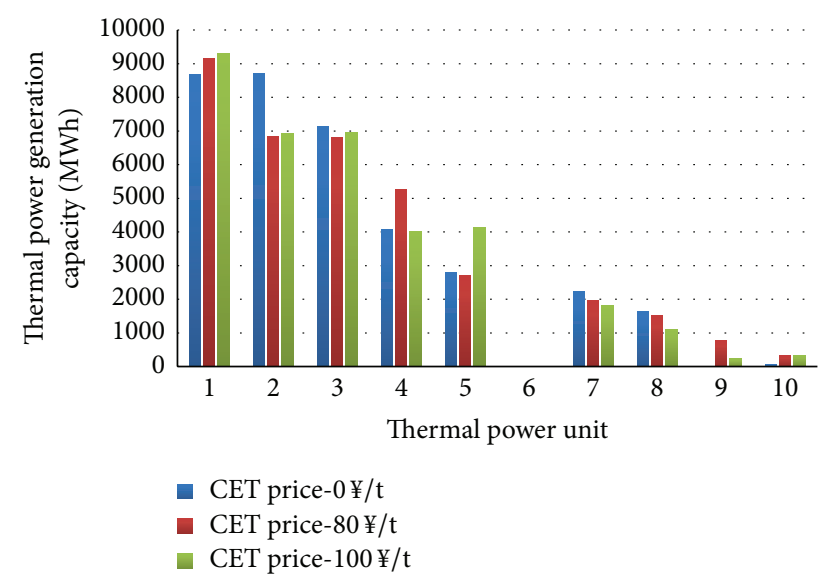

FIgURE 4: Comparison of thermal power generation under different carbon prices.

5.3.4. Case 4: Self-Scheduling of System with DR and CET. The synergistic effects of DR and CET on the joint scheduling problem are analyzed in Case 4 . The maximum wind power output was $19354.72 \mathrm{MWh}$. The curtailed wind power rate declined from $19.5 \%$ to $12.58 \%$. After introducing DR and CET, system coal consumption decreased to $314.82 \mathrm{~kg} / \mathrm{MWh}$. The maximum system profit was 3.1272 million yuan. The system optimization scheduling results under different cases are shown in Table 6.
In summary, DR leads to proper power consumption behavior, while system operation obtains an optimal result when introducing DR and CET at the same time. The comprehensive operation result of Case 4 is better than Cases 2 and 3 , which shows that a collaborative optimization effect exists for DR and CET. The curtailed wind power rate and coal consumption reach the minimum when DR and CET are both introduced.

\section{Conclusions}

The randomness of wind power output has become the primary impediment to wind power grid integration. To improve the system's capability to consume wind power, proper backup service should be provided on the generation side. Demand response should also be introduced to incentivize customers to respond to system scheduling. This paper constructs a joint optimization scheduling model for wind power and energy storage systems with CET and DR. The simulation results show the following:

(1) ESSs can provide backup service for wind power and increase the system's ability to consume wind power. However, total system generation profits would decrease due to the high fixed cost of ESSs. In the long term, China's large-scale ESS market has great potential with the establishment of a reasonable price mechanism and the development of mature energy storage technology.

(2) Demand response can optimize customers' power consumption behavior, smooth the demand load curve, and improve wind power grid integration. After introducing DR, wind power grid integration is enhanced, the system power structure becomes reasonable, thermal power costs are reduced, and the total system generation profit increases.

(3) Carbon emissions trading can increase the generation cost of thermal power units, enhance the advantages of integrating clean energy into the power grid, reduce the curtailed wind power rate, and optimize the system power structure. However, the total system generation profit is reduced due to the increased cost of thermal power generation.

(4) With the introduction of DR and CET, system operation and scheduling obtained an optimal result. The total system profit increased and the high cost of 
ESSs was reduced. In addition, the demand load curve was smoothed and the curtailed wind power rate and system coal consumption were reduced to the minimum. System profit increased to the maximum, which shows that a collaborative effect exists for DR and CET.

(5) Though the proposed model examined the optimization effect of ESSs, CET, and DR on wind power grid integration, some constraints related to practical applications are ignored for the sake of convenient analysis and reaching a conclusion.

\section{Nomenclature}

$t$ : $\quad$ Time index

$i$ : $\quad$ Thermal power unit index

$w$ : Wind farm index

$u$ : $\quad$ Binary variable: 1 means in operation; 0 means not in operation

$Q_{s, t}^{+}: \quad$ Charging power at time $t$

$Q_{s, t}^{-}: \quad$ Discharging power at time $t$

$\theta_{s}$ : Charging and discharging power loss coefficient

$\overline{Q_{s}}: \quad$ Upper limit for charging and discharging power

$Q_{s}^{\max }: \quad$ Maximum storage capacity of ESS

$\pi_{w}: \quad$ Wind farm profit

$\pi_{c}: \quad$ Thermal power unit profit

$\pi_{s}: \quad$ ESSs profit

$p_{c}$ : $\quad$ Benchmark price of thermal power

$Q_{i, t}$ : Real-time generation power of unit $i$ at time $t$

$\theta_{c, i}: \quad$ Power consumption rate of unit $i$

$C_{\text {fuel }}:$ Generation fuel cost

$\mathrm{OM}_{c, i}$ : Operation and maintenance cost of unit $i$

$D_{c, i}: \quad$ Depreciation cost of unit $i$

$p_{\text {coal }}: \quad$ Standard coal purchase price

$f_{i}\left(Q_{i, t}\right)$ : Standard coal consumption of unit $i$ at time $t$

$a_{i}, b_{i}, c_{i}$ : Coal consumption parameters of unit $i$

$\mathrm{SU}_{i}$ : $\quad$ Start-up cost of unit $i$

$\mathrm{SD}_{i}$ : $\quad$ Shutdown cost of unit $i$

$p_{s, \text { char }}$ : Electricity price when charging ESSs

$p_{s, \text { disc }}$ : Electricity price when discharging ESSs

$F_{s}: \quad$ Fixed cost of ESSs

$T_{i, t-1}^{\text {on }}$ : Running time of unit $i$ at time $t-1$

$T_{i, t-1}^{\text {off }}$ : Shutdown time of unit $i$ at time $t-1$

$M_{i}^{\text {on }}: \quad$ Shortest running time of unit $i$

$M_{i}^{\text {off }}$ : Unit shortest shutdown time of unit $i$

$\delta_{t}: \quad$ Equivalent utilization efficiency at time $t$

$P_{w}$ : Total installed capacity of wind farm $w$

$Q_{i, t}^{\max }: \quad$ Maximum possible output of unit $i$ at time $t$

$R_{t}^{\text {usr }}$ Upward spinning reserve demand at time $t$

$\overline{Q_{i}}: \quad$ Maximum possible energy generated by unit $i$ at time $t$

$\Delta Q_{i}^{+}: \quad$ Upward ramp rate of unit $i$ $\beta_{c}: \quad$ Thermal power unit reserve coefficient

$\beta_{w}$ : Power reserve coefficient for wind turbines

$Q_{i, t}^{\min }:$ Minimum possible output of unit $i$ at time $t$

$R_{t}^{\mathrm{dsr}}$ : Downward spinning reserve demand at time $t$

$Q_{i}: \quad$ Minimum possible generation capacity of unit $i$

$\Delta Q_{i}^{-}:$Downward ramp rate of unit $i$

$\mathrm{C}_{\mathrm{CO}_{2}}$ : Carbon emission cost

$E_{\mathrm{CO}_{2}}$ : Actual carbon emission of thermal unit during operation period

$E_{0}: \quad$ Total initial carbon emission right

$p_{\mathrm{CO}_{2}}$ : Carbon trading price.

\section{Competing Interests}

The authors declare that they have no competing interests.

\section{Acknowledgments}

This paper is supported by Beijing Union Cultivate Scientific Research Project and the Fundamental Research Funds of the Central Universities of China (2015XS29). Dr. Pan Ge helped in improving the language of the paper.

\section{References}

[1] J. Hetzer, D. C. Yu, and K. Bhattarai, "An economic dispatch model incorporating wind power," IEEE Transactions on Energy Conversion, vol. 23, no. 2, pp. 603-611, 2008.

[2] M. Grubb, T. Jamasb, and M. G. Pollitt, Delivering a Low-Carbon Electricity System, Cambridge University Press, 2008.

[3] IPCC, Climate Change 2007: The Physical Science Basis Contribution of Working Group I to the Fourth Assessment Report of the Intergovernmental Panel on Climate Change, Intergovernmental Panel on Climate Change, 2007.

[4] X. Yao, H. C. Zhou, A. Z. Zhang, and A. Li, "Regional energy efficiency, carbon emission performance and technology gaps in China: a meta-frontier non-radial directional distance function analysis," Energy Policy, vol. 84, pp. 142-154, 2015.

[5] S. H. Jiang, Z. C. Ji, and Y. Wang, "A novel gravitational acceleration enhanced particle swarm optimization algorithm for windthermal economic emission dispatch problem considering wind power availability," International Journal of Electrical Power \& Energy Systems, vol. 73, pp. 1035-1050, 2015.

[6] X. Yuan, H. Tian, Y. Yuan, Y. Huang, and R. M. Ikram, "An extended NSGA-III for solution multi-objective hydrothermal-wind scheduling considering wind power cost," Energy Conversion and Management, vol. 96, pp. 568-578, 2015.

[7] K. Y. Wang, X. J. Luo, L. Wu, and X. C. Liu, "Optimal coordination of wind-hydro-thermal based on water complementing wind," Renewable Energy, vol. 60, pp. 169-178, 2013.

[8] S. V. Papaefthymiou, V. G. Lakiotis, I. D. Margaris, and S. A. Papathanassiou, "Dynamic analysis of island systems with windpumped-storage hybrid power stations," Renewable Energy, vol. 74, pp. 544-554, 2015. 
[9] S. V. Papaefthymiou and S. A. Papathanassiou, "Optimum sizing of wind-pumped-storage hybrid power stations in island systems," Renewable Energy, vol. 64, pp. 187-196, 2014.

[10] Z. Ming, Z. Kun, and W. Liang, "Study on unit commitment problem considering wind power and pumped hydro energy storage," International Journal of Electrical Power and Energy Systems, vol. 63, pp. 91-96, 2014.

[11] X. Wu, X. L. Wang, J. Li, J. Guo, K. Zhang, and J. Chen, "A joint operation model and solution for hybrid wind energy storage systems," Proceedings of the Chinese Society of Electrical Engineering, vol. 33, no. 13, pp. 10-17, 2013.

[12] Z. Hu, H. Ding, and T. Kong, "A joint daily operational optimization model for wind power and pumped-storage plant," Automation of Electric Power Systems, vol. 36, no. 2, pp. 36-57, 2012.

[13] H. J. Ding, Z. C. Hu, and Y. H. Song, "Stochastic optimization of the daily operation of wind farm and pumped-hydro-storage plant," Renewable Energy, vol. 48, pp. 571-578, 2012.

[14] J. García-González, R. M. R. de la Muela, L. M. Santos, and A. M. Gonzalez, "Stochastic joint optimization of wind generation and pumped-storage units in an electricity market," IEEE Transactions on Power Systems, vol. 23, no. 2, pp. 460-468, 2008.

[15] L. A. Greening, "Demand response resources: who is responsible for implementation in a deregulated market?" Energy, vol. 35, no. 4, pp. 1518-1525, 2010.

[16] W. J. Niu, Y. Li, and B. B. Wang, "Demand response based virtual power plant modeling considering uncertainty," Proceedings of the Chinese Society of Electrical Engineering, vol. 34, no. 22, pp. 3630-3637, 2014.

[17] M. A. López, S. D. L. Torre, S. Martín, and J. A. Aguado, "Demand-side management in smart grid operation considering electric vehicles load shifting and vehicle-to-grid support," International Journal of Electrical Power \& Energy Systems, vol. 64, pp. 689-698, 2015.

[18] N. I. Nwulu and X. H. Xia, "Multi-objective dynamic economic emission dispatch of electric power generation integrated with game theory based demand response programs," Energy Conversion and Management, vol. 89, pp. 963-974, 2015.

[19] A. Ghasemi, S. S. Mortazavi, and E. Mashhour, "Hourly demand response and battery energy storage for imbalance reduction of smart distribution company embedded with electric vehicles and wind farms," Renewable Energy, vol. 85, pp. 124-136, 2016.

[20] J. H. Wang, C. Liu, D. Ton, Y. Zhou, J. Kim, and A. Vyas, "Impact of plug-in hybrid electric vehicles on power systems with demand response and wind power," Energy Policy, vol. 39, no. 7, pp. 4016-4021, 2011.

[21] L. W. Liu, C. X. Chen, Y. F. Zhao, and E. Zhao, "China's carbonemissions trading: overview, challenges and future," Renewable and Sustainable Energy Reviews, vol. 49, pp. 254-266, 2015.

[22] Y. Zhu, Y. P. Li, G. H. Huang, Y. R. Fan, and S. Nie, "A dynamic model to optimize municipal electric power systems by considering carbon emission trading under uncertainty," Energy, vol. 88, pp. 636-649, 2015.

[23] M. Khalid and A. V. Savkin, "Minimization and control of battery energy storage for wind power smoothing: aggregated, distributed and semi-distributed storage," Renewable Energy, vol. 64, pp. 105-112, 2014.

[24] L. W. Ju, Z. F. Tan, H. H. Li, X. Yu, and H. Zhang, "Multiobjective synergistic scheduling optimization model for wind power and plug-in hybrid electric vehicles under different grid-connected modes," Mathematical Problems in Engineering, vol. 2014, Article ID 179583, 15 pages, 2014.
[25] Z. F. Tan, L. W. Ju, H. H. Li, C. Qin, and D. Peng, "Multiobjective CVaR optimization model and solving method for hydrothermal system considering uncertain load demand," Mathematical Problems in Engineering, vol. 2015, Article ID 741379, 10 pages, 2015. 


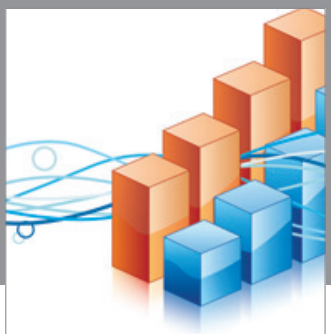

Advances in

Operations Research

vatem alat4

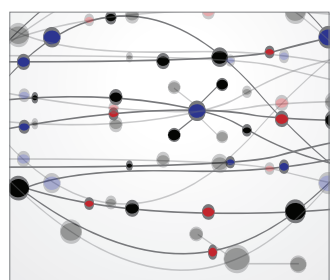

\section{The Scientific} World Journal
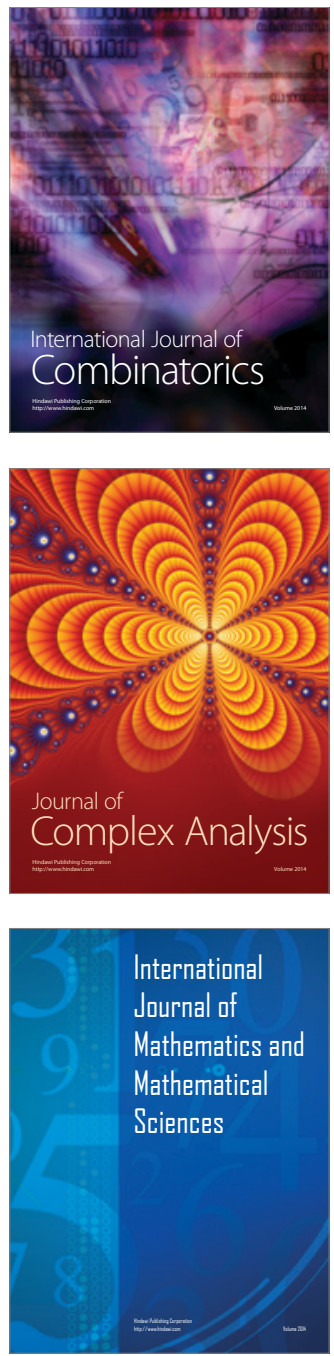
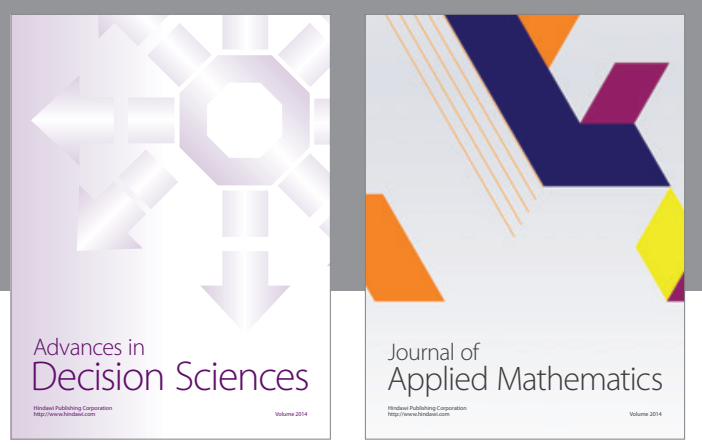

Algebra

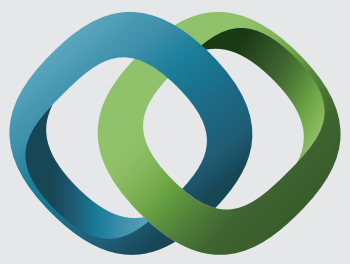

\section{Hindawi}

Submit your manuscripts at

http://www.hindawi.com
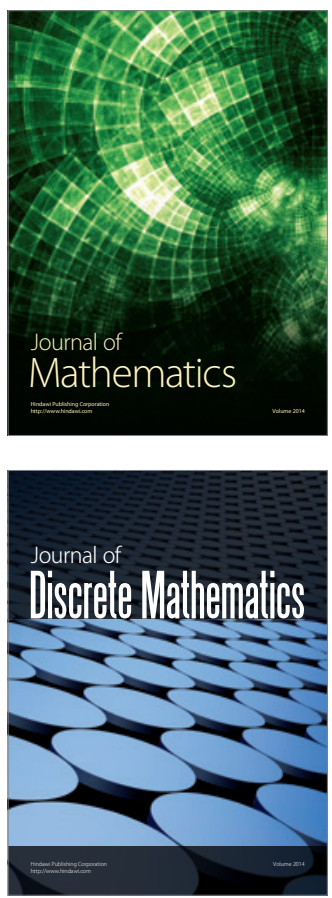

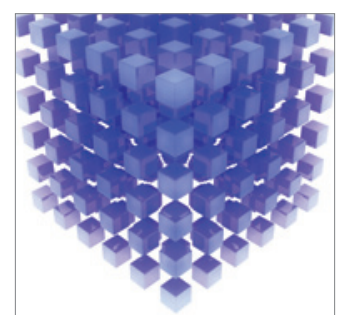

Mathematical Problems in Engineering
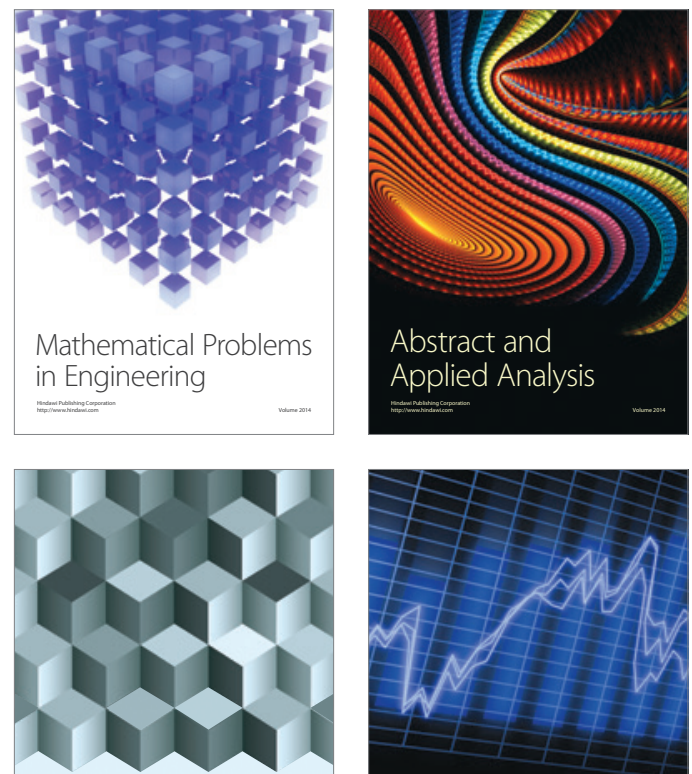

Journal of

Function Spaces

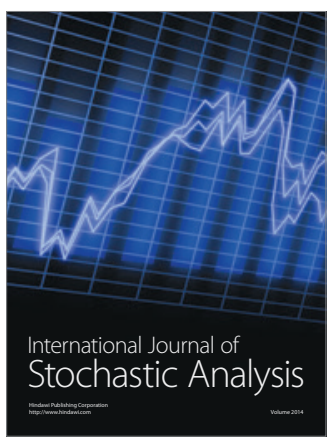

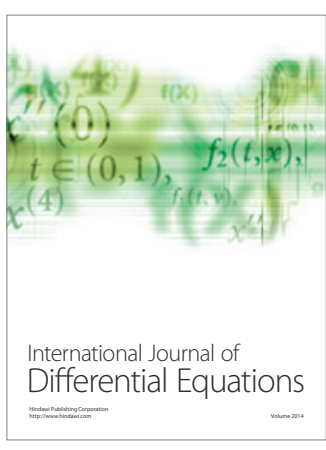
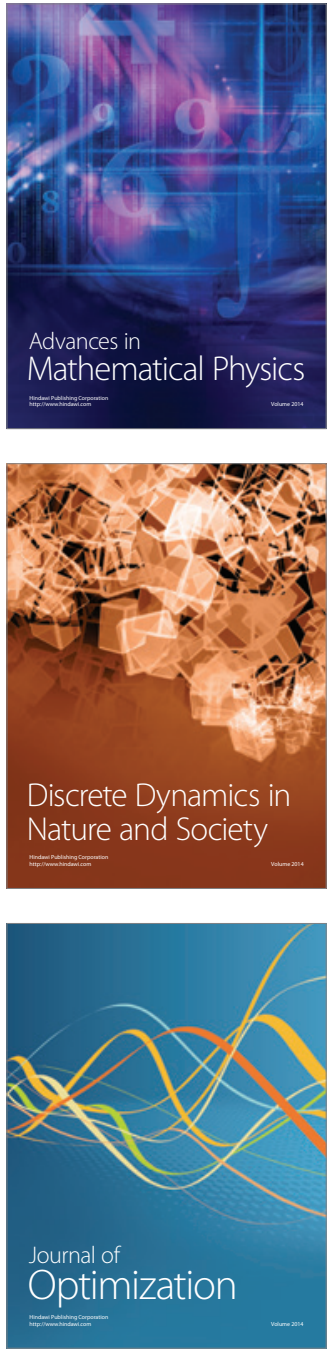